\title{
Tek Taraflı İnguinal Herni Operasyonu Uygulanan Çocuklarda Açık ve Laparoskopik Cerrahi Tekniklerinin Anestezi Süresi, Postoperatif Ağrı ve Analjezik Tüketimi Üzerine Etkilerinin Karşılaştırılması Comparison of the Effects of Laparoscopic and Open Repair Techniques on Postoperative Pain and Analgesic Consumption in Pediatric Unilateral Inguinal Hernia
}

\author{
Ferda Yılmaz İnal, Süleyman Çelebi* , Ali İhsan Uysal, Yadigar Yılmaz** , Mehmet Toptaş***, \\ Hayrettin Daşkaya**** \\ Tokat Devlet Hastanesi, Anestezi ve Reanimasyon Kliniği, Tokat, Türkiye \\ *Tokat Devlet Hastanesi, Çocuk Cerrahisi Kliniği, Tokat, Türkiye \\ **Sivas Devlet Hastanesi, Anestezi ve Reanimasyon Kliniği, Sivas, Türkiye \\ ***Haseki Eğitim ve Araştırma Hastanesi, Anesteziyoloji ve Reanimasyon Kliniği, İstanbul, Türkiye \\ ****Bezmialem Vakıf Üniversitesi Tıp Fakültesi, Anestezi ve Reanimasyon Anabilim Dalı, İstanbul, Türkiye
}

\section{Özet}

Amaç: Laparoskopik yöntemle inguinal herni operasyonları erişkinlerde avantajları nedeniyle tercih sebebi olsa bile çocuklarda halen tartışılmaktadır. Bu çalışmada tek taraflı inguinal herni operasyonu geçiren erkek çocuklarda açık ve laparoskopik cerrahi tekniklerinin anestezi süresi, postoperatif ağrı ve analjezik tüketimi üzerine etkilerini karşılaştırmayı amaçladık.

Yöntemler: Açık ve laparaskopik yöntemle inguinal herni operasyonu geçiren 7-14 yaşları arasındaki 40 erkek çocuk çalışmaya dahil edildi. Prospektif ve randomize olarak iki gruba ayrıldı. Tek taraflı açık inguinal herni grubu (AiH) n=20, tek taraflı laparoskopik inguinal herni grubu (LiH) n=20. Genel anestezi uygulanan hastaların anestezi süresi ve operasyon süresi kaydedildi. Postoperatif analjezi için hasta kontrolü analjezi (PCA) $0,01 \mathrm{mg} / \mathrm{kg}$ morfin bolus yapılarak başlandı. Bolus doz 0,01 mg/ kg, kilit zaman 10 dakika, 4 saat limit 4 mg olarak ayarlandı. Çocuklara periferik oksijen satürasyonları izlenerek postoperatif 24 saat süresince PCA uygulandı. Ağrı değerlendirmesi olarak Visuel Ağrı Skalası (VAS) $(0 \mathrm{~cm}$ : ağrı yok, $10 \mathrm{~cm}$ : düşünülebilecek en şiddetli ağrı) kullanıldı. PCA'da morfin kullanımına bağlı ortaya çıkabilecek yan etkiler olan solunum depresyonu, bulantı, kusma, kaşıntı, idrar retansiyonu takip edildi. Postoperatif 1., 2., 4., 12. , 24. saatlerde, $\mathrm{SpO}_{2}$, Ramsay Sedasyon Skoru (RSS), Numerik
Abstract

Aim: Although laparoscopic inguinal hernia $(\mathrm{IH})$ repair in adults is widely accepted, its advantages in pediatric age group are questionable. We aimed to compare the effects of open inguinal hernia repair and laparoscopic inguinal hernia repair on length of anaesthesia, postoperative pain and analgesic consumption in boys who underwent unilateral inguinal hernia repair.

Methods: Forty patients aged between 7 and 14 years who underwent open and laparoscopic inguinal hernia repair were included in this study. The patients were randomly divided into two groups: unilateral open inguinal hernia repair group (OR) $n=20$ and unilateral laparoscopic inguinal hernia repair group (LR) $n=20$. All patients underwent general anesthesia. The duration of anaesthesia and the duration of surgery were recorded. The Patient Controlled Analgesia (PCA) device was set at a $0.01 \mathrm{mg} / \mathrm{kg}$ bolus dose, 10 minutes lockout interval and 4 hour limit of $4 \mathrm{mg}$ morphine. The patients, who received morphine PCA for 24 hours postoperatively, were monitored with continuous oximetry. The Visual Analogue Scale (VAS) was used to measure pain $(0 \mathrm{~cm}$ : no pain, $10 \mathrm{~cm}$ : worst possible pain). We recorded the side effects of morphine, such as respiratory depression, nausea, vomiting, urinary retention, pruritus. $\mathrm{SpO}_{2}$ level and Ramsay Sedation Scale (RSS), Numerical Rating Scale (NRS), and Visual Analogue Scale (VAS) scores at intervals 1, 
Rank Skoru (NRS), Visual Analog Skoru (VAS), 24 saat süresince kullanılan PCA analjezik bolus miktarı ve istek sayısı kaydedildi. Postoperatif yürüme zamanı kaydedildi.-

Bulgular: Anestezi süresi ve operasyon süresi sırasıyla LïH grubunda 39,85 dk ve 28,85 dk, AiH grubunda 26,11 dk ve 20,53 dk ile LiH grubunda anlamlı derecede uzun bulundu $(p<0,001, p<0,01)$. VAS skorları ve yürümeye başlama zamanları her iki grupta benzer bulundu. Analjezik istek sayısı ve kullanım sayısı arasında istatistiksel olarak anlamlı fark bulunmadı. Ancak AiH grubunda PCA başarısız istek sayısı yüksekti. Morfin PCA'sına bağlı AiH grubunda bir çocukta Numerik Rank Skoru 2 olması dışında yan etki gözlenmedi. Periferik oksijen saturasyonları hiçbir çocukta \%95 altına düşmedi, Ramsay Sedasyon Skoru 2’nin üzerine çıkmadı.

Sonuç: Tek taraflı inguinal herni operasyonlarında, LiH yönteminde anestezi ve operasyon süresi daha uzun olsada, başarısız istek oranının yüksek olmasından dolayı çocukların $\mathrm{AiH}$ yönteminde daha fazla ağrı duydukları kanısıyla LiH yöntemi alternatif bir yöntem olarak düşünülebilir. (Haseki Tıp Bülteni 2014; 52: 84-8)

Anahtar Sözcükler: Çocuklar, tek taraflı açık ve laparaskopik inguinal herni, postoperatif ağrı, PCA

\section{Giriş}

Laparoskopik inguinal herni operasyonu (LiH), erişkinlerde hastanede kalış süresinin azlığı, erken fiziksel aktivite başlangıcı, daha küçük insizyon ile daha az doku hasarı sonucu daha az inflamatuar yanıt, daha az cerrahi stres, daha düşük postoperatif komplikasyon ve postoperatif ağrı skorunun düşük olacağı beklentisi nedeniyle tercih edilmektedir (1-5). Bununla birlikte LiH uzun operasyon süresi, ciddi komplikasyon (visseral ve vasküler yaralanma) riskinin yüksek olması ve yüksek maliyetle de ilişkilendirilmiştir (6).

Çocuklarda ise laparoskopik teknikle yapılan operasyonlar son 10 yılda artan sıklıkla tercih edilmeye başlanmıştır (7). Çocuklarda LiH operasyon deneyimlerini içeren bir seri çalışma mevcut olsa da açık veya laparoskopik operasyon seçiminde kabul edilebilen standart bir yöntem belirtilememiştir (8-10). Özellikle tek taraflı inguinal herni operasyonlarında laparoskopik yaklaşımın avantaj ve dezavantajları halen tartışılmaktadır.

Bu çalışmamızda prospektif ve randomize olarak tek taraflı inguinal herni operasyonu uygulanan 7-14 yaş arası erkek çocuklarda, açık ve laparoskopik cerrahi tekniklerinin anestezi süresi, postoperatif ağrı ve analjezik tüketimi üzerine etkilerini karşılaştırmayı amaçladık.

\section{Yöntemler}

$\begin{array}{llcc}\text { Gaziosmanpaşa Üniversitesi Tıp Fakültesi } & \text { Klinik } \\ \text { Araştırmalar Etik Kurulu'nun 12-KAEK-018 } & \text { kayıt } \\ \text { nolu 07.01.2013 tarihli onayı alındıktan sonra } & \text { Ocak }\end{array}$

$2,4,12,24$ hours as well as amount of analgesics consumed and number of requests within 24 hours postoperatively were recorded. Time to first walking was recorded.

Results: In group $\mathrm{OR}$, the mean duration of anaesthesia and surgery were 39.85 minutes and 28.85 minutes, respectively. In group LR, the mean duration of anaesthesia and surgery were 26.11 and 20.53 minutes, respectively. VAS scores and time to first walking were similar in both groups. There was no significant difference in amount of analgesics consumed and number of request between the two groups. In group $O R$, the number of unsuccessful requests was higher than in group LR. There was not any side effects except for a higher NRS score of higher than 2 in one patient. Peripheral oxygen saturation was never less than $95 \%$. RSS scores were never higher than 2.

Conclusion: Higher number of unsuccessful request implies that children who undergo an open inguinal hernia repair feel more pain, thus, it can be thought that laparoscopic hernia repair is an alternative technique although the duration of anaesthesia and surgery was significantly longer in unilateral laparoscopic inguinal hernia repair technique. (The Medical Bulletin of Haseki 2014; 52: 84-8)

Key Words: Boys, unilateral open and laparoscopic inguinal hernia repair, postoperative pain, PCA

2013-Haziran 2013 tarihleri arasında yapılan çalışmaya açık ve laparaskopik yöntemle inguinal herni operasyonu geçiren ASA I-II, 7-14 yaşları arasındaki 40 erkek çocuk dahil edildi. Çocukların ebeveynleri bilgilendirilip onamları alındı. Çalışma prospektif ve randomize olarak planlandı. Sistemik enfeksiyonu, kardiyak, renal, hepatik, endokrin, metabolik hastalığı, mental motor geriliği olan ve kooperasyon kurmada güçlük yaşanan hastalar çalışmaya dahil edilmedi.

Tüm çocuklar operasyondan $30 \mathrm{dk}$ önce $0,3 \mathrm{mg} / \mathrm{kg}$ nazal midazolam ile premedike edildi. Operasyon odasına alınan çocuklar monitorize edilerek $22 \mathrm{G}$ kanül takılarak damar yolu açıldı. Anestezi indüksiyonu için IV $1 \mu \mathrm{g} / \mathrm{kg}$ fentanil, $5-7 \mathrm{mg} / \mathrm{kg}$ tiyopental, $0,6 \mathrm{mg} / \mathrm{kg}$ rokuronyum verildi. Endotrekeal entübe edildikten sonra mekanik ventilasyona geçildi (8-10 ml/kg). Anestezi idamesi \%50 O2 - \%50 hava karışımı inspirasyon sonundaki sevofluranın MAC (minimum alveolar konsantrasyon) değeri \%2-\%3 arasında olacak şekilde sevofluran konsantrasyonu ayarlandı.

Çocuklar rastgele iki gruba ayrıldı. Tek taraflı açık inguinal herni grubu $(\mathrm{AiH}) \mathrm{n}=20$, tek taraflı laparoskopik inguinal herni grubu $(\mathrm{LiH}) \mathrm{n}=20$. AiH grubuna açık cerrahi teknik, LiH grubuna ise laparoscopic partial excision ve purse-string tekniği (by Montupet) uygulandı.

Laparoskopik prosedür esnasında abdominal basınç 10-12 $\mathrm{mmHg}$ arasında sabit tutuldu. Anestezi süresi ve operasyon süresi kaydedildi. 
Operasyon bitiminde hastalar atropin ve neostigmin ile revers edildi. Uygun şartlar sağlanarak ekstübe edilen hastalar derlenme odasına alındı. Derlenme ünitesinde postoperatif analjezi için hasta kontrolü analjezi (PCA) $0,01 \mathrm{mg} / \mathrm{kg}$ morfin bolus yapılarak başlandı. Bolus doz $0,01 \mathrm{mg} / \mathrm{kg}$, kilit zaman 10 dakika, 4 saat limit $4 \mathrm{mg}$ olarak ayarlandı. Ağrı değerlendirmesi olarak Visuel Ağrı Skalası (VAS) $(0 \mathrm{~cm}$ : ağrı yok, $10 \mathrm{~cm}$ : düşünülebilecek en şiddetli ağrı) kullanıldı. Bolus morfin $(0,01 \mathrm{mg} /$ $\mathrm{kg}$ ) dozuna rağmen VAS>4 olduğunda çocuklara ek analjezi olarak $15 \mathrm{mg} / \mathrm{kg}$ parasetamol iv olarak verilmesi planlandı.

Çocuklara periferik oksijen satürasyonları izlenerek postoperatif 24 saat süresince PCA uygulandı. Çocuklarda ağrı skorları aynı araştırmacı tarafından sorgulandı ve sözel olarak öğrenilerek kaydedildi.

PCA da morfin kullanımına bağlı ortaya çıkabilecek yan etkiler olan solunum depresyonu, bulantı, kusma, kaşıntı, idrar retansiyonu takip edildi. Solunum depresyonu, solunum sayısı ve Ramsey sedasyon skoruna göre değerlendirildi) (Tablo 1), bulantı kusma ise Numerik Rank Skoruna (0: bulantı kusma yok; 1: bulantı var, kusma yok; 2: bir kez kusma var; 3: iki veya daha fazla kusma atağı var) göre tanımlandı.

Postoperatif 1., 2., 4., 12., 24. saatlerde, $\mathrm{SpO}_{2}$, Ramsay Sedasyon Skoru, Numerik Rank Skoru ve Visual Analog Skoru (VAS) kaydedildi. Yirmi dört saat süresince kullanılan PCA analjezik bolus miktarı ve istek sayısı kaydedildi. Yirmi dört saat sonrasında PCA sonlandırıldı. Postoperatif yürüme zamanı kaydedildi.

\section{İstatistiksel Değerlendirme}

Istatistiksel analizler için SPSS for windows 10.0 istatistik paket programı kullanıldı. Karşısş̧ıımalarda Student's t test, Mann-Whitney $U$ test ANOVA ve tukey HSD testleri kullanıldı. P<0,05 anlamlı olarak kabul edildi.

\section{Bulgular}

Çalışmada grupların yaşları karşılaştııılığında istatistiksel olarak anlamlı bir fark bulunmadı $(p>0,05)$ (Tablo 2).

Anestezi sürelerive operasyon sürelerikarşılaştırıldığında LiH grubunda AiH grubuna göre istatistiksel olarak anlamlı derecede uzun bulundu ( $p<0,001, p<0,01)$ (Tablo 3).

Postoperatif ağrı skorları değerlendirmesinde gruplar arası VAS değerlerinde istatistiksel olarak anlamlı bir fark bulunmadı $(p>0,05)$ (Tablo 4) (Şekil 1).
Analjezik kullanım miktarlarına bakıldığında ise istek sayısı ve kullanım sayısı arasında istatistiksel olarak anlamlı bir fark tesbit edilmedi $(p>0,05)$ (Tablo 5).

Her iki grup arasında yürümeye başlama zamanları arasında bir fark görülmedi ( $p>0,05)$ (Tablo 6).

Yan etki izleminde kaşıntı ve idrar retansiyonu hiçbir çocukta görülmedi. Solunum depresyonu ve apne kaydedilmedi. Periferik oksijen satürasyonu hiçbir çocukta \%95'in altına düşmedi, Ramsay Sedasyon Skoru ise 2'nin üzerine çıkmadı. Bulantı kusma takibinda AiH grubunda bir çocukta 2. saat NRS 2 olması dışında NRS 1'in üzerine çıkmadı.

\section{Tartışma}

Tek taraflı inguinal herni operasyonu uygulanan erkek çocuklarda açık ve laparoskopik cerrahi tekniklerinin anestezi süresi, postoperatif ağrı ve analjezik tüketimi üzerine etkilerini karşılaştırdığımız bu çalışmamızda laparoskopik yöntemde anestezi ve operasyon süresinin uzun olduğunu, postoperatif ağıı skorlarının ve analjezik tüketiminin benzer olduğunu ancak istatistiksel olarak anlamlı çıkmasada açık yöntemde PCA'da başarısız istek sayısının yüksek olduğunu gözlemledik. Postoperatif yürümeye başlama sürelerinde de fark görmedik. Bunu da postoperatif ağrı tedavisinde kullandığımı PCA yönteminin etkinliğine bağladık.

Anestezi ve operasyon süresi yapılan birçok çalışmada LiH grubunda uzun olarak bildirilmiş (11-15). Bizim çalışmamızda da diğer çalışmalarla benzer şekilde operasyon süresi LiH grubunda 28 dakika, AiH grubunda 20 dakika ile LiH grubunda anlamlı derecede uzun bulundu. Anestezi süresi ise $\mathrm{LiH}^{\prime}$ de 39 dakika, AiH'de 26 dakika ile uzundu. Operasyon süresi LïH grubunda \%40 oranında artarken anestezi süresinin $\% 50$ artmasını ise laparoskopik cihaz ve aletlerin hazırlık aşamasının uzun

Tablo 1. Ramsay Sedasyon Skoru

1 Hasta ajite ve huzursuz

2 Koopere, oryante, sakin

3 Uyuyor, sözlü uyarıya yanıt var

4 Uyuyor, ağrılı uyarıya ılımlı yanıt var

5 Uyuyor, ağrılı uyarıya yavaş yanıt var

6 Uyuyor, ağrılı uyarıya yanıt yok

Tablo 2. Grupların yaş ortalamaları

\begin{tabular}{|l|l|l|l|l|l|}
\hline & \multicolumn{2}{|c|}{ AiH Grubu } & \multicolumn{2}{c|}{ LiH Grubu } & \\
\hline & Ortalama & SS & Ortalama & SS & p \\
\hline Yaş & 7,84 & 2,34 & 8,15 & 2,38 &, 909 \\
\hline
\end{tabular}


Tablo 3. Anestezi ve operasyon süreleri (dakika)

\begin{tabular}{|l|l|l|l|l|l|}
\hline & \multicolumn{2}{|c|}{ AiH Grubu } & \multicolumn{2}{c|}{ LiH Grubu } & SS \\
\hline & Ortalama & SS & Ortalama & 9,65 & 3,14 \\
\hline Anestezi süresi & 26,11 & 7,38 & 28,85 &, $000 * * *$ &, $005^{* *}$ \\
\hline Operasyon süresi & 20,53 & 7,42 & & & \\
\hline$* *: p<0,01, * * *: p<0,001$ & & & & \\
\hline
\end{tabular}

Tablo 4. Visuel Ağrı Skalası (0-10 cm) değerleri

\begin{tabular}{|c|c|c|c|c|c|}
\hline \multirow[b]{2}{*}{ VAS } & \multicolumn{2}{|c|}{ AïH Grubu } & \multicolumn{2}{|c|}{ LiH Grubu } & \multirow[b]{2}{*}{$\mathbf{p}$} \\
\hline & Ortalama & SS & Ortalama & SS & \\
\hline 1. saat & 4,47 & 3,06 & 3,62 & 3,04 &, 432 \\
\hline 2. saat & 1,47 & 2,17 & 2,30 & 1,83 &, 531 \\
\hline 4. saat & 1,36 & 1,95 & 1,44 & 1,25 & 926 \\
\hline 12. saat & 93 & 1,62 & 1,00 & 2,07 & 907 \\
\hline 24. saat & 20 & ,77 &, 00 & 1,73 & ,807 \\
\hline
\end{tabular}

Tablo 5. AiH Grubu ve LiH Grubu Analjezik istek ve kullanım sayıları

\begin{tabular}{|l|l|l|l|l|l|}
\hline & \multicolumn{3}{|c|}{ AiH Grubu } & \multicolumn{3}{c|}{ LiH Grubu } & SS & p \\
\hline istek & Ortalama & SS & Ortalama & 7,29 &, 170 \\
\hline Kullanım & 33,24 & 6,24 & 10,70 & 6,08 &, 187 \\
\hline
\end{tabular}

Tablo 6. Yürümeye başlama zamanı (dakika)

\begin{tabular}{|l|l|l|l|l|l|}
\hline & \multicolumn{2}{|c|}{ AiH Grubu } & \multicolumn{2}{|c|}{ LiH Grubu } & SS \\
\hline Yürüme & Ortalama & SS & Ortalama & p \\
\hline
\end{tabular}
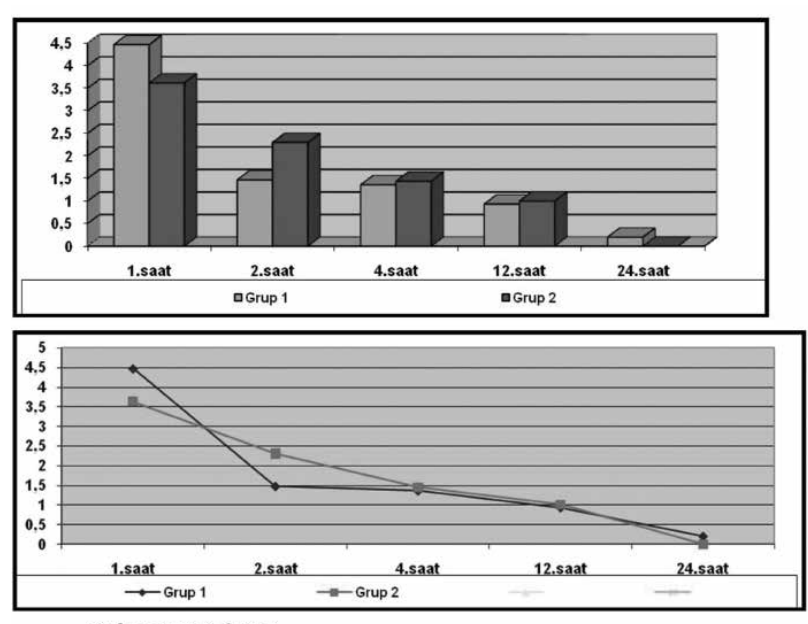

Y ekseni: VAS değeri

X ekseni: 1, 2, 4, 12,24 saatler

Şekil 1. Grup 1 ve 2 VAS grafiği sürmesine bağladık. Daha iyi bir ekip çalışması ile bu sürenin kısaltılabileceğini düşünüyoruz.

Postoperatif ağrı değerlendirilmesinde Chan ve ark.'nın yaptığı çalışmada ağı skorları 4 veya 5 üzerine çıkınca Asetaminofen $15 \mathrm{mg} / \mathrm{kg} / 6 \mathrm{~h}$ oral uygulamışlar. LiH grubunda daha az analjezik tüketimi bildirmişlerdir (11). Antti ve ark.'nın çalışmasında hastalara postoperatif ihtiyaç duyduklarında fentanyl $1 \mathrm{mcg} / \mathrm{kg}$ olarak uygulamışlar ve hemen analjezik uygulama öncesi ağı skorlarını kaydetmişlerdir. LiH grubunda daha fazla analjezik tüketimi (LiH: \%79, AiH: \%42) olduğunu belirtmişler. Ağrı skorları arasında ise anlamlı bir fark bulmamışlar (12). Hossain ve ark. ise LïH grubunda düşük ağrı skorları kaydetmişler (16).

Çalışmamızda postoperatif analjezide optimal ağrı kontrolü, yüksek hasta-aile mennuniyeti ile beraber güvenli ve efektif bir ağrı yönetimi sağlayan PCA yöntemini tercih ettik (17-21). PCA da hastanın kendi denetimindeki bolus dozlar sayesinde ağrı kesici ihtiyacı duyduğu zamanla ağrı 
kesici uygulanması arasında bekleme süresi olmaması avantajını kullandık (18).

Biz bu çalışmada ise postoperatif ağrı değerlendirmesinde sözel iletişim kurabilen ve kavramları gelişen yedi yaş üzeri çocuklarda $0-10 \mathrm{~cm}$ arasında VAS skorlaması uyguladık. Hastalara ağrılarını $4 \mathrm{~cm}$ ve üzeri olarak değerlendirdikleri zaman PCA cihazına basmaları istedik. Bu nedenle her iki grup VAS skorları arasında bir fark bulmadık. Analjezik istek sayısı ve kullanım sayısı arasında da istatistiksel olarak anlamlı fark çıkmasa da AiH grubunda istek sayısı ortalamasının 33,24, LiH grubunda ise 10,70 olmasını klinik olarak anlamlı değerlendirdik. AïH grubunda başarısız istek sayısı yüksekliği bize çocukların daha fazla ağrı duyduğunu ve daha fazla hasta sayısı olan çalışmalara intiyaç olduğunu düşündürttü.

Postoperatif analjezi için kullandığımız PCA yönteminde morfin kullanımına bağlı yan etkilerin (solunum depresyonu, apne, sedasyon, kaşıntı, idrar retansiyonu, bulantı, kusma) AilH grubunda bir çocukta olan bulantı, kusma haricinde görülmemesi yöntemi çocuklarda da güvenle kullanabileceğimizi destekledi. VAS skorlarında her iki grupta da en yüksek 4,47 ortalama olması ise analjezi tedavisindeki etkinliği gösterdi.

Postoperatif ağrı tedavisindeki etkinliğin ise postoperatif yürüme sürelerine yansıdığını ve her iki grup arasında fark olmamasına neden olduğunu düşündük.

Sonuç olarak, çalışmamızda LiH yönteminde anestezi ve operasyon süresinin daha uzun olsada, AiH yönteminde başarısız istek oranının yüksek olmasından dolayı çocukların daha fazla ağrı duydukları kanısıyla tek taraflı inguinal herni operasyonlarında LiH yöntemi alternatif olarak düşünülebilir.

\section{Kaynaklar}

1. McCormack K, Scott NW, Go PM, Ross S, Grant AM; EU Hernia Trialists Collaboration. Laparoscopic techniques versus open techniques for inguinal hernia repair. Cochrane Database Syst Rev 2003;:CD001785.

2. Butler RE, Burke R, Schneider JJ, Brar H, Lucha PA Jr. The economic impact of laparoscopic inguinal hernia repair: resultsof a double-blinded, prospective, randomized trial. Surg Endosc 2007;21:387-90.

3. Eklund A, Rudberg C, Smedberg S, et al. Short-term results of a randomized clinical trial comparing Lichtenstein open repair with totally extraperitoneal laparoscopic inguinal hernia repair. Br J Surg 2006;93:1060-8.

4. Arvidsson D, Berndsen FH, Larsson LG, et al. Randomized clinical trial comparing 5-year recurrence rate after laparoscopic versus Shouldice repair of primary inguinal hernia. Br J Surg 2005;92:1085-91.
5. MRC Laparoscopic Groin Hernia Trial Group. Laparoscopic versus open repair of groin hernia: a randomized comparison. Lancet 1999;354:185-90.

6. McCormack K, Wake B, Perez J, et al. Laparoscopic surgery for inguinal hernia repair: systematic review of effectiveness and economic evaluation. Health Technol Assess 2005;9:1-203, iii-iv.

7. Laberge JM. What's new in pediatric surgery. J Am Coll Surg 2002;195:208-18.

8. Schier F. Laparoscopic surgery of inguinal hernias in childreninitial experience. J Pediatr Surg 2000;35:1331-5.

9. Schier F, Montupet P, Esposito C. Laparoscopic inguinal herniorrhaphy in children: a three-center experience with 933 repairs. J Pediatr Surg 2002;37:395-7.

10. Rangel SJ, Henry MC, Brindle M, Moss RL Small evidence for small incisions: pediatric laparoscopy and the need for more rigorous evaluation of novel surgical therapies. J Pediatr Surg 2003;38:1429-33.

11. Chan KL, Hui WC, Tam PK. Prospective randomized singlecenter, single-blind comparison of laparoscopic vs open repair of pediatric inguinal hernia. Surg Endosc 2005;19:927-32.

12. Koivusalo Al1, Korpela R, Wirtavuori K, Piiparinen S, Rintala RJ, Pakarinen MP. A single-blinded, randomized comparison of laparoscopic versus open hernia repair in children. Pediatrics 2009;123:332-7.

13. Saha N, Biswas I, Rahman MA, Islam MK. Surgical outcome of laparoscopic and open surgery of pediatric inguinal hernia. Mymensingh Med J 2013;22:232-6.

14. Alzahem A. Laparoscopic versus open inguinal herniotomy in infants and children: a meta-analysis. Pediatr Surg Int 2011;27:605-12.

15. Nah SA1, Giacomello L, Eaton S, et al. Surgical repair of incarcerated inguinal hernia in children: laparoscopic or open ? Eur J Pediatr Surg 2011;21:8-11.

16. T Hossain, K Hasina, AU Huq A Comparative Study between the Outcome of Laparoscopic Repair and Open Repair of Paediatric Inguinal Hernia-Bangladesh Journal of Endosurgery, 2013 vol 1, No 2.

17. Franson HE. Postoperative patient-controlled analgesia in the pediatric population: a literature review. AANA J 2010;78:374-8.

18. Chiaretti A, Genovese O, Antonelli A, et al. Patient controlled analgesia with fentanil and midazolam in children with postoperative neurosurgical pain. Childs Nerv Syst 2008;24:119-24.

19. Verghese ST, Hannallah RS. Acute pain management in children. J Pain Res 2010;3:105-23.

20. Ruggiero A, Barone G, Liotti L, Chiaretti A, Lazzareschi I, Riccardi R. Safety and efficacy of fentanyl administered by patient controlled analgesia in children with cancer pain. Support Care Cancer 2007;15:569-73.

21. Anghelescu DL, Burgoyne LL, Oakes LL, Wallace DA. The safety of patient-controlled analgesia by proxy in pediatric oncology patients. Anesth Analg 2005;101:1623-7. 